\title{
Aspirado de médula ósea y aplicación de plasma autólogo plaquetario como factor de regeneración de tejidos, mi experiencia.
}

\section{Bone marrow extraction and application of autologous plaquetary plasma as a tissular regenerating factor, my experience.}

\author{
Suárez Oyhamburú, D. *, Schaymann Lora, J. ** \\ *Cirujano Plástico Titular SBCPER, FILACP; IPRAS, Clínica Niño Jesús Dos, Santa Cruz de la Sierra, Bolivia \\ ** Bioquímica Farmacéutica, MD. Coordinadora de gestión hospitalaria, Regente del Laboratorio de la \\ Clínica Médica Sirani, Centro de fertilización asistida Clínica Sirani, Santa Cruz de la Sierra, Bolivia.
}

\section{Resumen.}

El presente artículo muestra una conducta terapéutica de la medicina regenerativa como alternativa para el tratamiento de distintas patologías clínico quirúrgicas en el área de la Cirugía Plástica, Estética y Reconstructiva. Nosotros iniciamos este trabajo a partir de enero del año 2006 hasta marzo del presente año.

Al hablar de factores regeneradores autólogos de tejidos nos referimos a la aplicación de Factores de Crecimientos(FC), obtenidos del plasma plaquetario de sangre venosa periférica así como de la Fracción Vascular Estromal(FVE), obtenida por punción aspiración de medula ósea del hueso esternal durante el mismo acto quirúrgico, procesado y aplicado según el caso clínico.

Uno de los efectos alcanzados es una mayor aceleración en el proceso de granulación, mejoría y evolución del proceso de cicatrización tanto de partes blandas como óseas en distintas patologías como fracturas multi fragmentarias , cierre de fistulas sinoviales, quemaduras e integración de injertos , traumatismos de partes blandas, así como la aplicación también en casos de cirugías estéticas, donde conseguimos además de un efecto hemostático a manera de tapón como en las rinoplastias, una mayor tersura, hidratación , plasticidad, renovación celular, preservación de lipo injertos a largo plazo y regeneración cutánea.
Fueron 132 casos de mi consultorio privado tratados con esta terapia regenerativa, de los cuales en 97 pacientes empleamos los factores de crecimiento mediante el plasma plaquetario autólogo aplicando 1 sesión para los de cirugías estética y entre 3 a 4 sesiones para los pacientes de cirugía reconstructiva, con intervalos de 5 días.

En 35 pacientes aplicamos la Fracción Vascular Estromal (FVE) a través del aspirado de la médula ósea de la región esternal empleando como máximo de contenido 7 a $10 \mathrm{mls}$. Para que no exista lesión de los sinusoides medulares.

Aunque actualmente venimos aplicando ambos procedimientos terapéuticos como terapia conjunta de rutina en nuestro servicio para los casos indicados, aportando así una carga muy alta de citocinas y tal vez en menor proporción células tronco.

Palabras Clave: Factores Regeneradores Autólogos, Citocinas, Fracción Vascular Estromal de Medula Ósea, Células Tronco Mesenquimales.

\section{Abstract.}

The present article shows a therapeutic conduct of regenerative medicine, as an alternative treatment for different clinical pathologies in Esthetic and Reconstructive Plastic Surgery. We started this project on January 2006 and continue through March of the present year. 
By referring to these autologous regenerative tissues factors, we talk about the uses of Growth Factors, withdrawn from the plaquetary plasma from peripherical blood, and the Stromal Vascular Fraction obtained by aspiring it from the bone marrow of the sternum during the same surgery procedure to apply it to each medical case.

One of the effects reached was the acceleration on the process of granulation, a better healing of soft tissues and on bones of different pathologies such as multi fragmentary fractures, closures of synovial fistula, burns and flaps integrations, soft tissues traumatism, application on esthetical surgery to obtain a hemostatic effect as on rhinoplastic procedures, improve terseness, skin hydration, plasticity, tissular renewable, optimization on the fat implant integration and skin regeneration.

There were 132 private patients treated with this regenerative therapy, in which 97 of them we used growth factors obtain from autologous plaquetary plasma once during the surgery procedure and three or four times for those patients who had reconstructive surgery, with five days intervals.

In 35 patients we used the stromal vascular fraction obtained from the bone marrow of the sternal region a maximum of 7 to $10 \mathrm{ml}$ so that there wouldn't be any sinusoidal injure.

Actually we have been using both therapeutical procedure for any clinical case that is recommended for every patient, contributing a great amount of cytokines and perhaps a lesser one of stem cells.

Key Words: Autologous Regenerative Factors, Cytokines, Stromal Vascular Fraction from Bone Marrow, Mesenchymal Stem Cells.

\section{Introducción.}

Los Factores de crecimiento (FC) son glucoproteinas o citocinas que afectan el comportamiento celular, uniéndose a receptores de membrana plasmática de alta afinidad que actúan de forma localizada (efectos autócrinos), aunque también tienen efectos parácrinos y endocrinos. (1-3).

Se encuentran en el interior de los gránulos Alfa en las plaquetas, los cuales son liberados cuando normalmente se producen los fenómenos inflamatorios y reparativos en una herida. Seguidamente estas proteínas interactúan con una hormona mediadora que se llama "Tirosinquinasa ", la cual estimula la mitosis celular a nivel del núcleo de la célula receptora (6-8). Varios son los factores de crecimiento conocidos o estudiados y cada uno está destinado a actuar o ejercer el efecto que le corresponda sobre los tejidos blandos o duros, así como también en el proceso de cicatrización normal de una herida. (1-5-6). Por ejemplo, en la fase inflamatoria de la cicatrización actúan: Factor derivado de plaquetas (PDGF) y el Factor transformador beta (TGF-B). En la segunda fase Proliferativa o de fibroplasia, actúan el Factor de crecimiento Fibroblástico (FGF), el epidérmico (EGF) y tal vez el más importante que asegura la re-vascularización de los tejidos, el VEGF.Y finalmente en la última fase de maduración celular es el Factor Transformador Beta tipo dos (TGF beta 2). (1-2-6).

En una publicación el Dr. Barry Eppley y sus colaboradores de la Universidad de Indiana, en EUA, determinaron que a través del test de Elisa era posible cuantificar la concentración de cada factor de crecimiento, encontrándose el Factor vascular endotelial (VEGF) 6.2 veces en mayor proporción, alcanzando una concentración de $110 \mathrm{pg} / \mathrm{ml}$ a $1030 \mathrm{pg} / \mathrm{ml}$.

En segundo lugar se encuentra el Factor de crecimiento derivado de plaqueta (PDGF), 5.1 veces, alcanzando una concentración de o,9 ng/dl a $8 \mathrm{ng} / \mathrm{dl}$.

En tercer lugar está el Factor de crecimiento epidérmico (EGF), con 3.9 veces. Alcanzando una concentración de 61 $\mathrm{pg} / \mathrm{dl}$ a $317 \mathrm{pg} / \mathrm{dl}$.

Y finalmente en cuarto lugar el Factor transformador Beta 2, encontrándose 3.6 veces aumentado, alcanzando de $8 \mathrm{ng} /$ dl a 42ng/dl su concentración. (1-2).

Con respecto a la Fracción Vascular Estromal (FVE), esto es un segmento del tejido conectivo localizado alrededor del árbol vascular, donde además se localizan las células tronco hematopoyéticas y las mesenquimales en importante cantidad, así como también las células madres endoteliales de la médula ósea(8-9-10). Las cuales se pueden únicamente diferenciar con marcadores celulares de superficie específicos para cada tipo celular.

El tejido adiposo es capaz de formar al menos 5 veces en mayor cantidad las Unidades Formadoras de Colonias (CFU), es decir existen 5000 CFU por cada gramo de tejido adiposo y en el caso de la medula ósea se encuentran de 100 a 1000 CFU por ml de tejido medular aspirado. (9-10).

Como ya es de conocimiento general, el tejido graso aporta con la mayor cantidad de células madre mesenquimales en relación al tejido de la médula ósea...tanta es la diferencia cuantitativa que la concentración es 50 veces mayor a favor del tejido graso.(7-8-9-10) Esto hace hoy en día, la posibilidad de desarrollar mayores expectativas y/o resultados cuando a través de procesos enzimáticos de biodegradación, con posterior cultivo y expansión celular se pueda tener a la mano la posibilidad de la utilización de estas células.

Debido a las dificultades técnicas propias, ausencia de recursos económicos en las universidades del estado y/o privadas que realicen profundas investigaciones en el área 
además de las limitaciones económicas de mi país, hace que solo trabajemos con la FVE de la médula ósea, asociemos esta opción terapéutica a la aplicación de los factores de crecimiento y conjuntamente otorguemos a los tejidos lesionados una gran carga de Citocinas y en menor proporción, pero presentes al final y al cabo una cantidad de células madre, prestas a participar en los procesos reparativos que sean necesarios.

Todos los casos descritos y presentados en el presente artículo hacen parte de una gama interesante de pacientes de mi consulta privada, atendidos normalmente en el día a día o en las salas de emergencia donde practico mi actividad profesional.

\section{Material y métodos.}

En cuanto a la de los Factores de crecimiento, lo realizamos por colecta de sangre venosa periférica, entre 10 a $40 \mathrm{mls}$, dependiendo de la indicación medico terapéutica a realizar.

Esta toma de muestra se la realiza en momentos previos al acto quirúrgico en sí, inclusive antes de canalizar una vía venosa, para evitar hemodilución. Se coloca la muestra sanguínea en tubos con citrato de calcio al $3.8 \%$, posteriormente se realiza la centrifugación a una velocidad de 1800 rpm por 8 minutos. La división de las fases del plasma en plasma rico (PRP) y Plasma Pobre (PPP) la realizamos bajo una estricta medida de seguridad biomédica dentro de una cámara con campana de flujo laminar para evitar contaminaciones del medio ambiente y mantenemos las dos fases por separadas en un termostato a temperatura ambiente para evitar desestabilización del plasma obtenido y/ o contaminación de dicha muestra, hasta que pudiera ser utilizado.

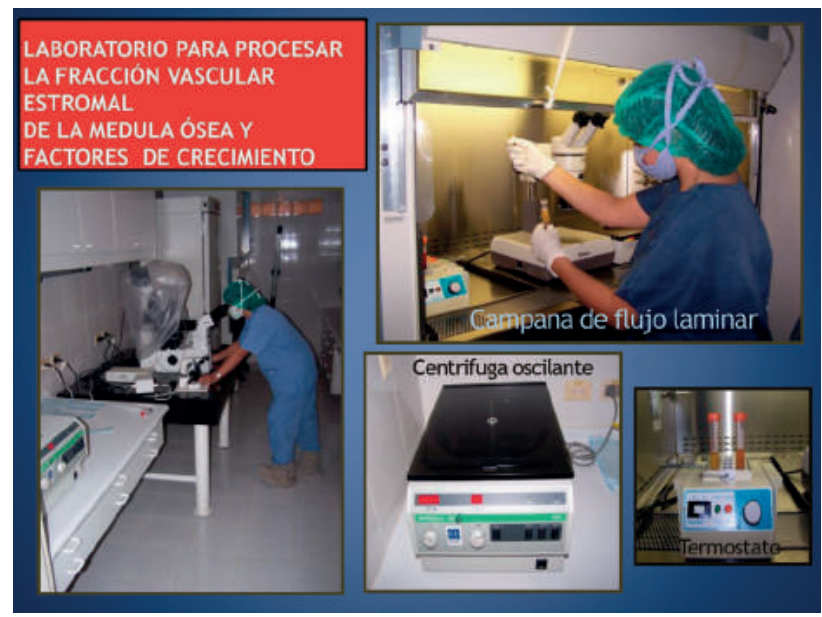

En la actualidad usamos ambas fases del plasma por separados, es decir tanto el PRP como el PPP, este último segmento aunque contenga una pequeña cantidad de plaquetas tiene efectos adherentes en los tejidos, además de las cualidades presentes de todo contenido plasmático.
Finalmente activamos la muestra plasmática con Cloruro de Calcio al $10 \%$, logrando una serie de sucesos en las plaquetas que termina con el "rompimiento" plaquetario, es decir se produce lo que llamamos.... "SHOCK OSMOTICO", porque a nuestra manera de pensar la palabra "rompimiento " no nos parece técnicamente adecuada. Figura 2. Además de esta liberación, se conforma un tapón hemostático plaquetario solido y macizo.

Consiguientemente luego de producido el" shock osmótico plaquetario" se produce finalmente la verdadera liberación de los "gránulos alfa" quienes contienen en su interior los factores de crecimiento. Figura 2.

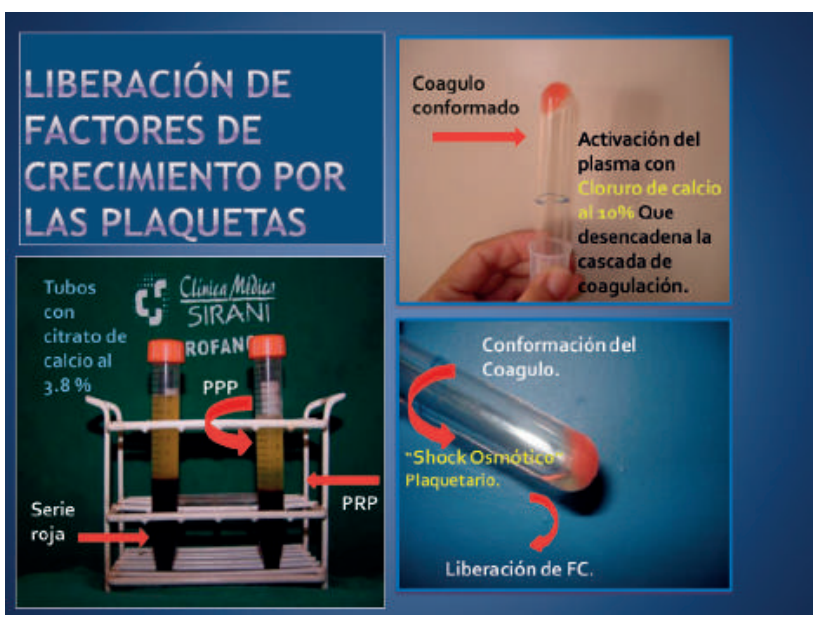

En nuestro protocolo no usamos el gluconato de calcio en el lugar del cloruro de calcio, porque al no existir un intercambio iónico celular inmediato, la simple y mera aplicación del gluconato retardaría la liberación consiguiente de los factores de crecimiento. Entonces es fácil comprender que a mayor concentración del cloruro de calcio más rápidamente se producirá lo que denominamos "Shock Osmótico Plaquetario".

Infelizmente cada vez nos cuesta mucho utilizar o disponer del cloruro de calcio, debido a la dificultad y a la logística que implica la aplicación de este producto, ya que en nuestro país el flagelo del narcotráfico y el enriquecimiento ilícito empleado inescrupulosamente para dañar nuestra humanidad, usan esta solución para la fabricación de cocaína, necesitando cada vez justificaciones técnicas y los permisos correspondientes en las instancias gubernamentales necesarias para liberarnos el uso adecuado y científico del cloruro de calcio.

La Fracción Vascular Estromal (FVE) la obtenemos a través de la punción aspiración del hueso esternal momentos previos al inicio de la cirugía, realizando asepsia y antisepsia adecuada del área, empleando una dosis profiláctica de una cefalosporina, como la cefalotina y/o cefotaxima endovenosa. Seguidamente con una jeringa de $20 \mathrm{mls}$ en cuyo 
contenido se encuentran $2.5 \mathrm{mls}$ de heparina sódica y con una aguja rosada $18 \mathrm{~g}$, se realizan a nivel del cuerpo del hueso esternal, movimientos de rotación hasta horadar la primera capa ósea, en este momento debemos muchas veces cambiar la aguja $18 \mathrm{~g}$ por otra similar, pues se taponea de restos óseos para poder realizar la aspiración del material medular entre más o menos 7 a 10 mls. Figura 3.

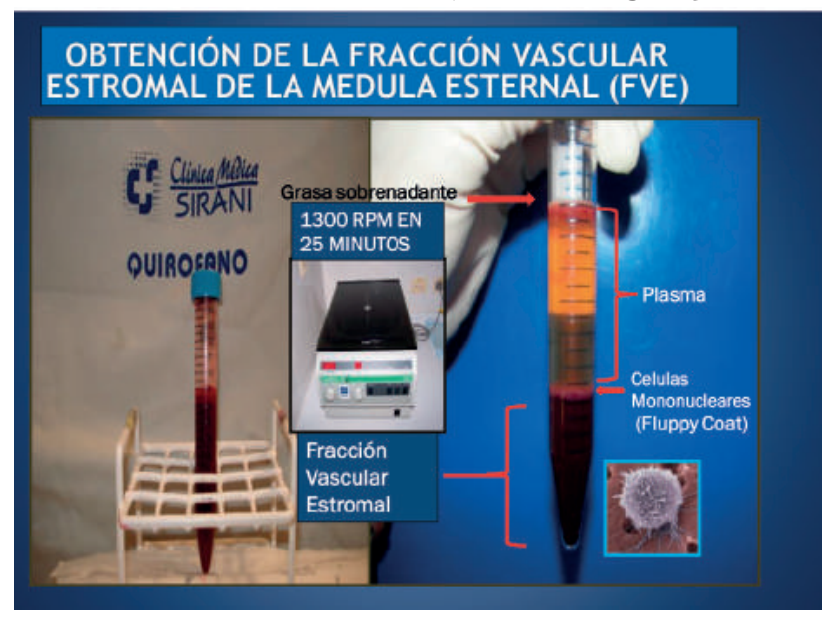

Posteriormente centrifugamos la muestra a $1300 \mathrm{rpm}$ en 25 minutos, obteniendo así diferentes densidades en el tubo de ensayo, encontrándose de arriba hacia abajo la grasa propia del tejido medular, la cual se encuentra en mayor proporción en pacientes seniles debido al proceso substitutivo propio de la edad, en segundo nivel encontramos el plasma en sus dos fases, el cual descartamos. En tercer lugar encontramos un segmento fino llamado "Fluppy coat" que contienen una gran cantidad de células mono nucleares, las cuales al principio las desechábamos pero fuimos aprendiendo debido a la curva de aprendizaje en todo periodo de investigación que este segmento es muy útil debido a función importante que cumplen "in situ" una gran concentración de estas células. Y finalmente en el último segmento del tubo de ensayo se encuentra la FVE. Dicho segmento es una estructura tridimensional altamente organizada, donde se encuentran células del estroma, matriz extracelulary una alta concentración de citocinas. En este micro ambiente se encuentra además de las células hematopoyéticas, 4 tipos celulares como fibroblastos estromales, macrófagos, adipositos y osteoblastos prestos a diferenciarse 0 actuar cuando reciban las señales precisas, gracias al efecto de las citocinas, como las interleucinas y los factores estimuladores de colonia.(9).

Las células madre son células que tienen la potencialidad de generar otras células iguales a ellas o de auto regenerarse dando lugar a células hijas de las mismas características.

Es relevante también comprender que el envejecimiento celular se debe al acortamiento progresivo y programado de los telomeros, que son estructuras presentes al final del cromosoma, y que cada vez que la célula se divide para reproducirse, estas estructuras se acortan mas y mas, entrando entonces la célula en un proceso degenerativo terminal programado llamado apoptosis y muere. Sin embargo la "telomerasa " que es una enzima presente en el DNA celular, actúa restaurando el tamaño inicial de los telomeros retardando de esta manera el envejecimiento y la muerte celular programada en condiciones normales, sin que existan agentes agresores externos.

Acostumbramos irónicamente a decir que tal vez deberíamos consumir tabletitas de "telomerasa" para prolongar nuestras vidas!!! Quien sabe de esta manera podríamos alcanzar la tan añorada juventud eterna!

Creemos importante hacer hincapié que únicamente empleamos la FVE de la medula ósea y nuestro grupo no realiza cultivos celulares ni expansión de tejidos debido a las dificultades tecnológicas y limitaciones económicas propias de nuestro país ya mencionadas con anterioridad.

\section{Resultados.}

Tratamos a 132 pacientes con esta terapia regenerativa desde el año 2006 hasta marzo del 2015, de los cuales 97 pacientes empleamos los FC autólogos y los otros 35 pacientes aplicamos la FVE de médula ósea asociándolos también conjuntamente con los FC.

Debido a la numerosidad de los pacientes mostraremos únicamente los casos clínicos más importantes y significativos cuya evolución clínico quirúrgica alcanzo resultados interesantes.

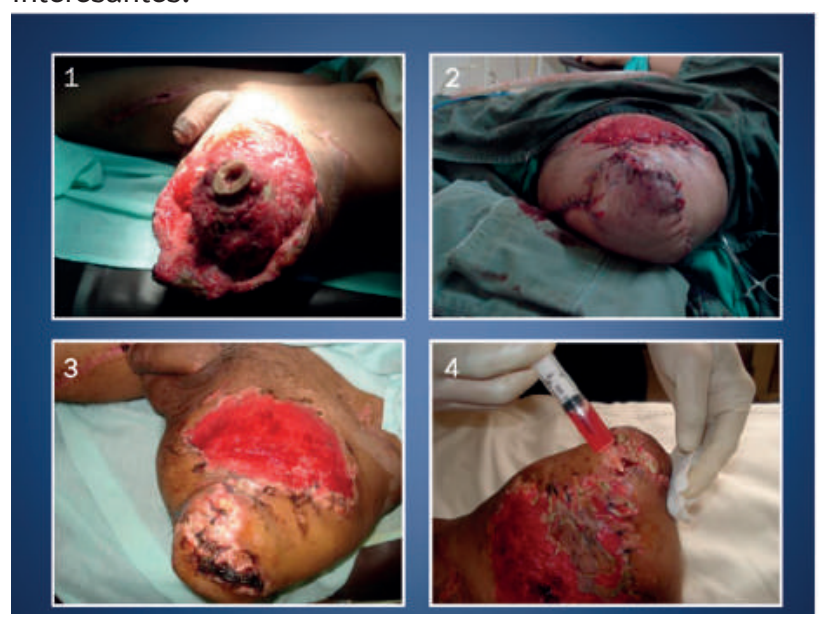

En la figura 4, mostramos un caso de una amputación traumática del miembro inferior durante un accidente laboral, en cual realizamos colgajos miocutáneos de rotación para cubrir el segmento del hueso del fémur expuesto de la pierna izquierda y en el post operatorio evoluciono con dehiscencia de tejidos y exposición del muñón óseo. Aplicamos 
3 a 4 sesiones de Factores de Crecimiento autólogos, una cada semana, realizamos injertos de las áreas expuestas con rotación y avances de colgajos locales en menor proporción y conseguimos el cierre o cobertura del segmento óseo expuesto salvando así el muñón en el lapso de 2 meses luego del inicio de la terapia regenerativa.(figura 5.)
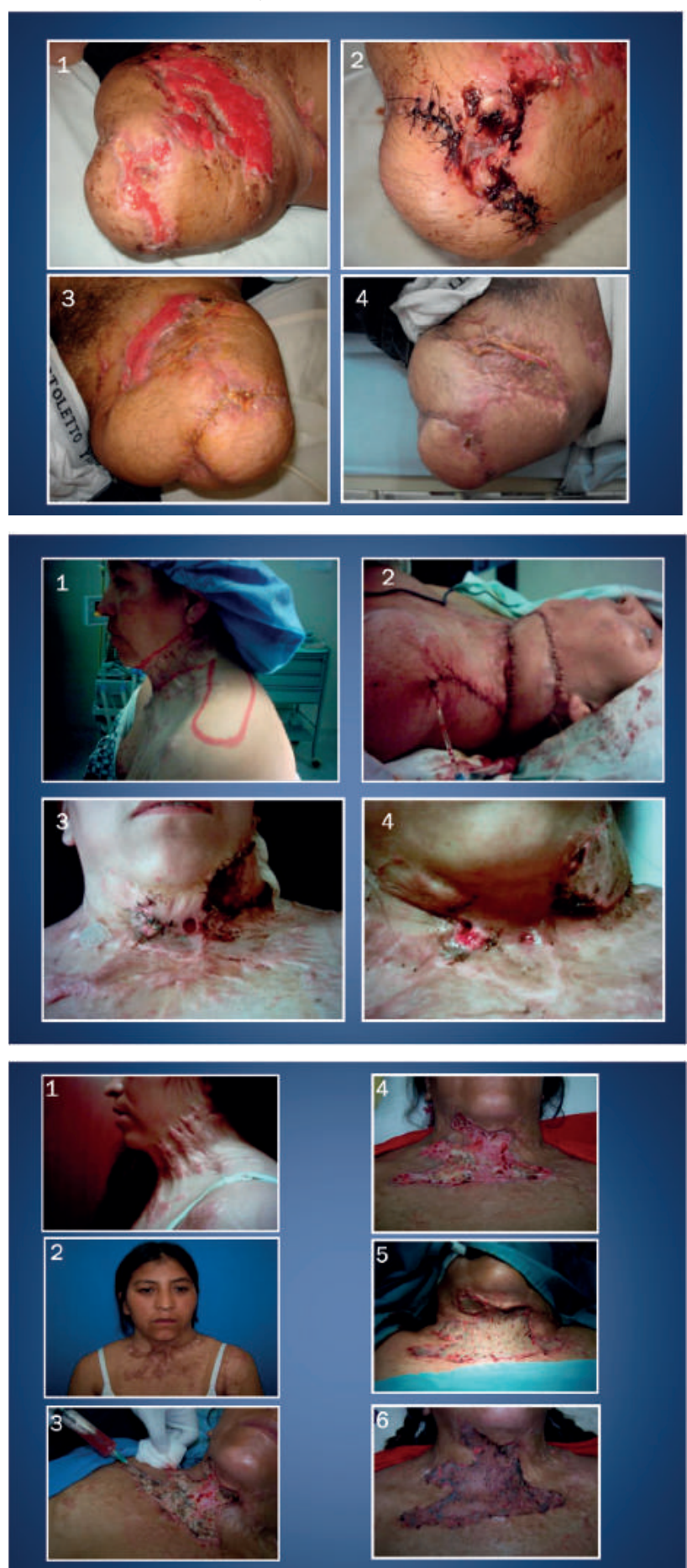

En la figura 6, uno de los primeros casos donde empleamos los factores de crecimiento en una paciente con secuelas de quemaduras, presentando retracciones cicatriciales impor- tantes que impedían los movimientos cervico faciales, realizamos una rotación de colgajo Fasciocutáneo en Charretera, evolucionando con una fistula y un pequeño foco infeccioso que fue tratado con antibiótico terapia convencional. Dicho cuadro se acompaño de epidermólisis en la punta del colgajo rotado. Realizamos una sola sesión de FC, mostrando una mejoría notable a los 7 días post aplicación.(Figura 7), 6 meses posteriores, la paciente es sometida nuevamente a lipoaspiracion del colgajo para su adelgazamiento, exceresis de la cicatriz retráctil cervical, una única aplicación de FC en el lecho receptor, donde evidenciamos una mejoría en la granulación del tejido y 7 días después realizamos injertos autólogos , observando una integración del 99 \% del área injertada, como muestra la secuencia y evolución.
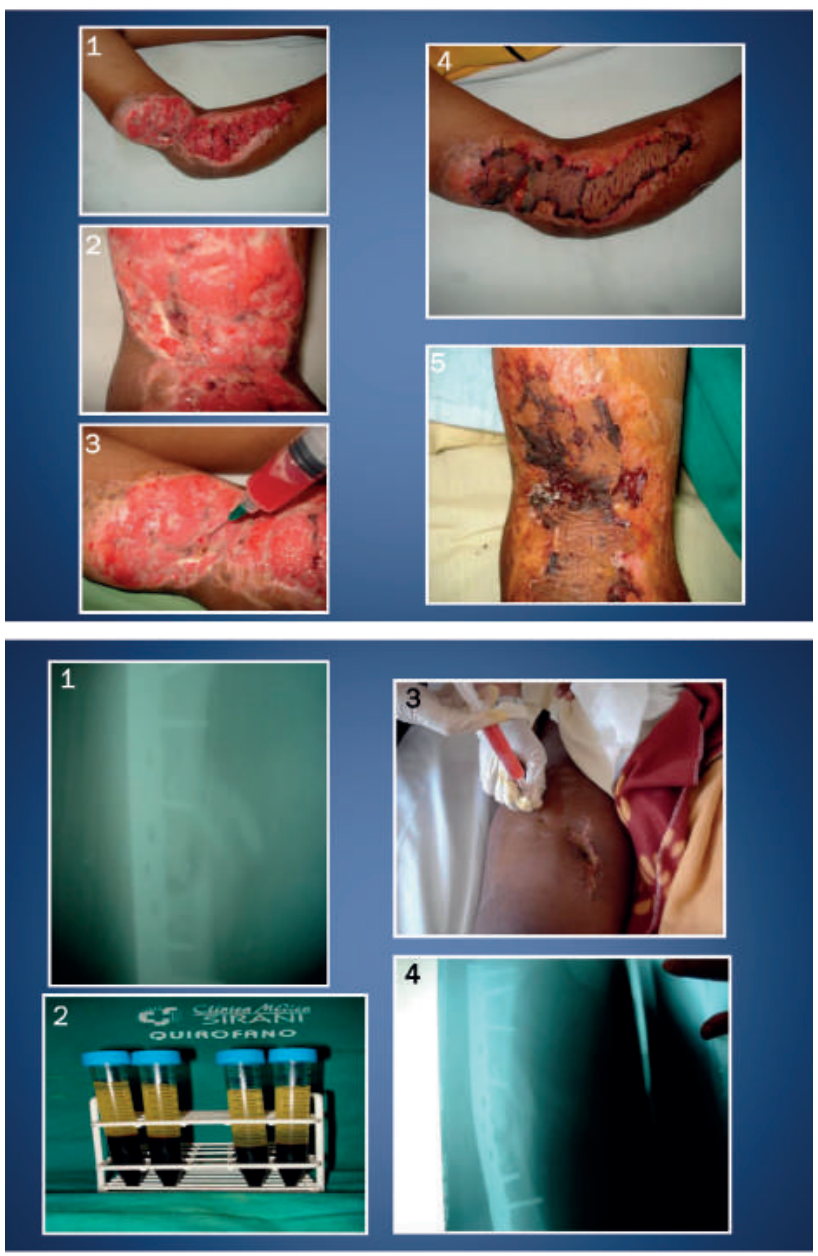

En la figura 8, podemos observar un paciente con una fractura del codo del brazo derecho, pérdida de substancia que había evolucionado favorablemente y además una fistula Sinovial que impedía la colocación de un injerto autólogo de piel, motivo por el que fuimos llamados y aplicamos una sola sesión de FC en el trayecto de la fistula y en el tejido de granulación lo que nos permitió realizar injertos autólogos con una integración del 98 \% y una evolución favorable con el cierre total de la fistula sinovial. 
En la Figura 9, un herido de bala con fractura ósea multi fragmentaria en fémur derecho, tratado quirúrgicamente con placas y tornillos, aplicamos dos sesiones de FC en una semana con un intervalo entre 3 días entre sesión y sesión y tomamos a los 7 días una nueva radiografía convencional donde observamos una mayor compactación de los múltiples segmentos óseos.

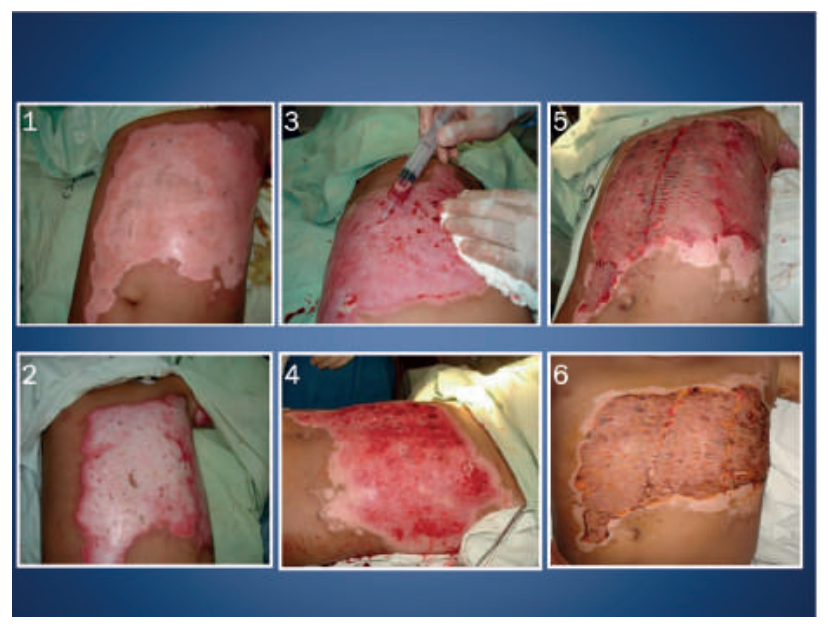

El siguiente caso de la figura 10, se trata de un niño quemado accidentalmente cuando jugaba con fuego del encendedor, prendiéndose fuego la camiseta y presentando quemaduras de $3 e r$. Grado y un $12 \%$ de SCQ. Las cuales no mejoraban con las curaciones rutinarias en quirófano realizadas en nuestro protocolo de tratamiento de quemados. Entonces aplicamos a los 8 días post quemadura los FC en el lecho del área quemada que presentaba mucha fibrina y ausencia de granulación, lo que normalmente retarda el proceso de colocación de injertos. Aplicamos 2 sesiones de FC como se observa en las fotos y conseguimos una aceleración de la granulación con el consiguiente injerto autólogo 9 días post quemadura y la integración total del injerto a los 15 días post lesión. Optimizando el tiempo de internación y reduciendo además los costes de lo esto significa en un centro privado.

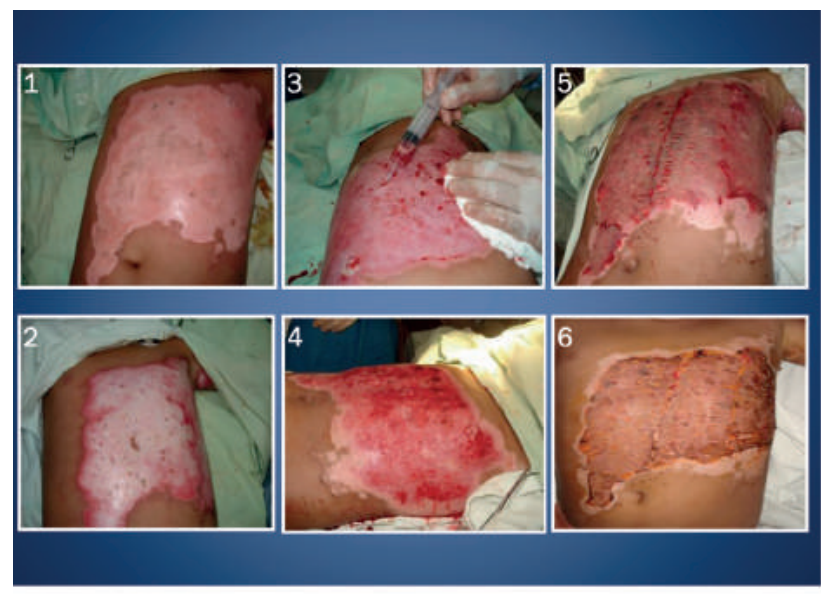

Figura 11. Este caso muestra una paciente de 18 años con una malformación facial producto de una sinequia labio auricular del lado izquierdo, la cual había sido intervenida quirúrgicamente durante su infancia lo que causo una atrofia hemi lateral por fibrosis de los tejidos. Fue tratada con lipo transferencia de tejidos autólogos provenientes de la región abdominal, particularmente solo decantamos la grasa, no realizamos lavado ni centrifugado, asociamos los factores de crecimientos autólogos y además aplicamos la FVE de la médula ósea. En las imágenes 2 y 2.a podemos apreciar un año de evolución donde aun se preserva la grasa injertada, observamos mejoría de la calidad cutánea, evolución favorable del acné, un mejor brillo y tersura de la piel que se manifiesta como un tejido más suave al tacto.

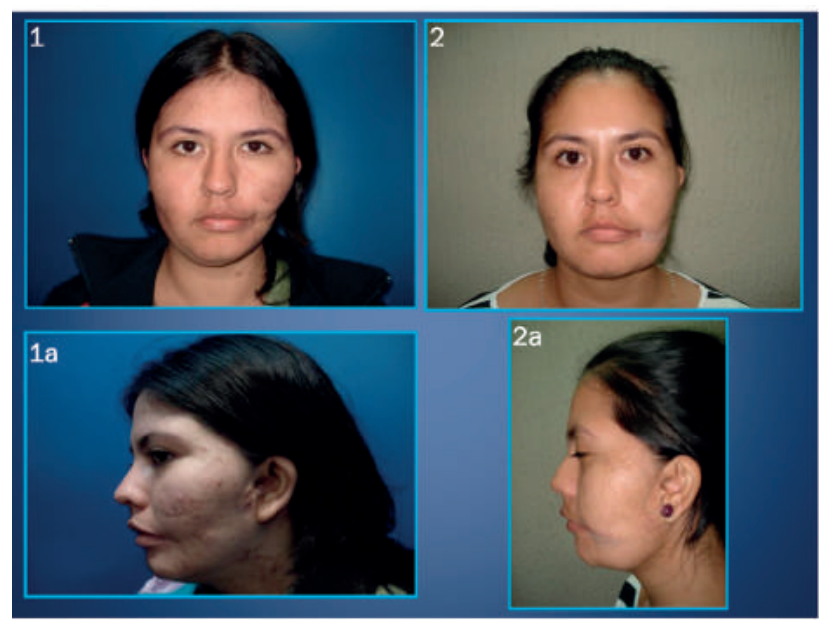

En las imágenes siguientes del mismo caso, Figura 12. Podemos comparar el pre operatorio ( 1 y 1.a) con las imágenes 2 y 2.a con 4 años y 6 meses de evolución, donde aun a pesar de los años de evolución observamos los mismos cambios alcanzados con cuando tenía apenas un año de evolución pero llama la atención la preservación del injerto de grasa y las características de la piel.

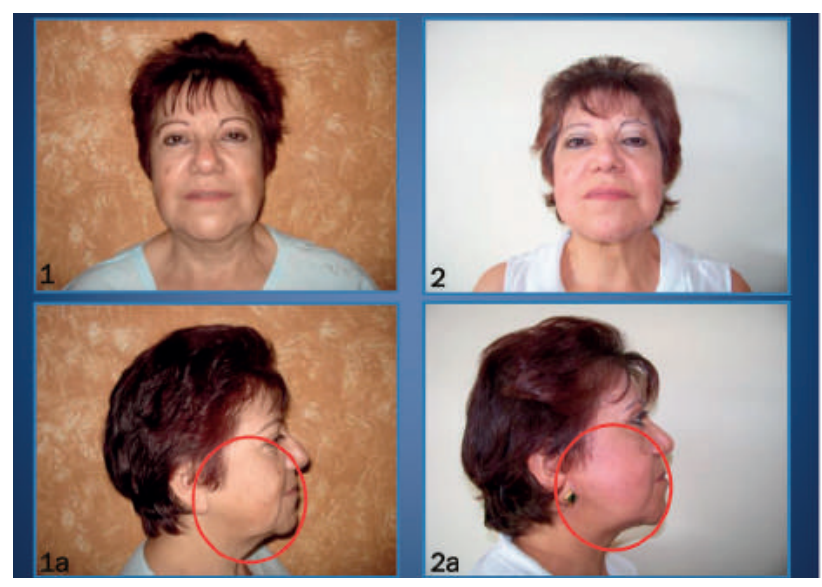

Figuras 13, imágenes 1y 1.a muestran un paciente candidata a lifting facial, donde la calidad de la piel es típica de las per- 
sonas que viven en las regiones altas de nuestro país, debido a la exposición solary al viento helado, marcan las características típicas de cutis envejecidos, secos e inexpresivos. Y en las imágenes de al lado 2 y 2.a demuestran 2 años de evolución, donde se observan cambios regenerativos de la piel, mayor tersura, mayor hidratación, menor sequedad, esto tal vez por la carga alta de citocinas inyectadas.
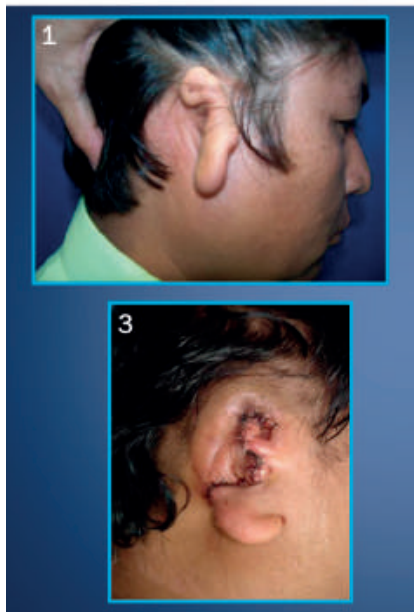
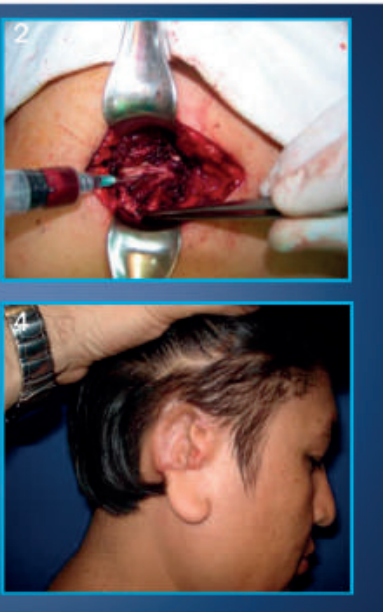

Finalmente mostramos en las figuras consecutivas dos casos interesantes de malformaciones del pabellón auricular, la primera, Figura 14, donde presentamos un caso de $\mathrm{Mi}$ crotia Severa lado derecho, según la clasificación del Prof. Juárez Avelar, (ausencia de CAE, presencia de lóbulo y restos cartilaginosos) en un hombre de 45 años. Donde además demostramos que a nivel del 8 avo. Espacio intercostal derecho inyectamos la FVE de medula ósea en el mismo conducto pericondrial de donde obtenemos el segmento cartilaginoso que vendrá a ser el futuro pabellón auricular.
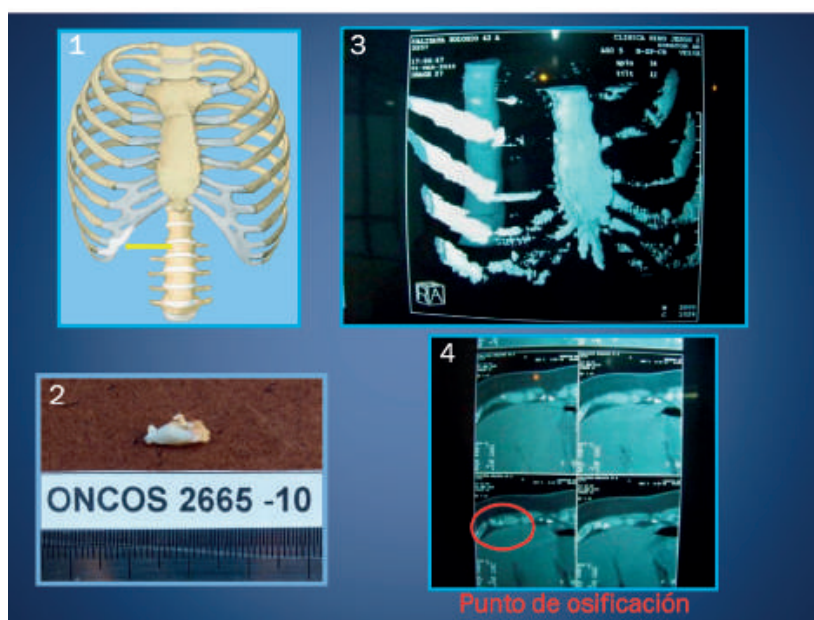

En las Figuras 15, el segmento biopsiado macroscópicamente y una tomografía de tórax a los 6 meses de Post operación donde nos muestra un foco periférico de calcificación en segmento donde inyectamos la FVE de médula ósea.

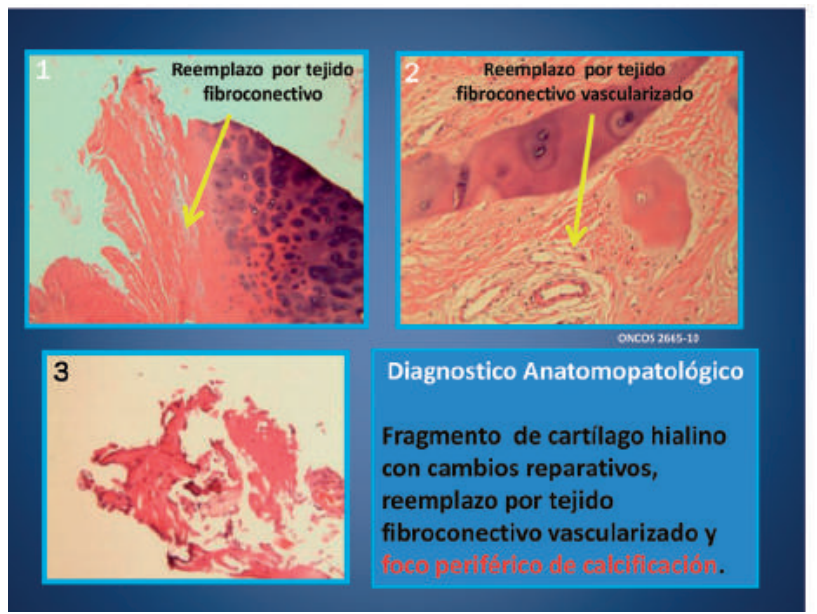

Y en la Figura 16. Mostramos a los 6 meses de Post operación una biopsia realizada en el mismo lugar donde inyectamos la FVE y obtuvimos como reporte de anatomía patológica lo siguiente: Fragmento de cartílago hialino, con cambios reparativos con reemplazo de tejido fibroconectivo vascularizado y foco periférico de calcificación. Este reporte coincide con el informe tomográfico, lo que concluimos que la señal enviada a las células tronco de la FVE era regenerar tejidos similares a los retirados para reconstruir el pabellón auricular de acorde con la edad del paciente. Es decir al tener un paciente de 45 años solo se formaría tejidos cartilaginosos fibrosados, endurecidos o calcificados, propios de esa faja etaria.

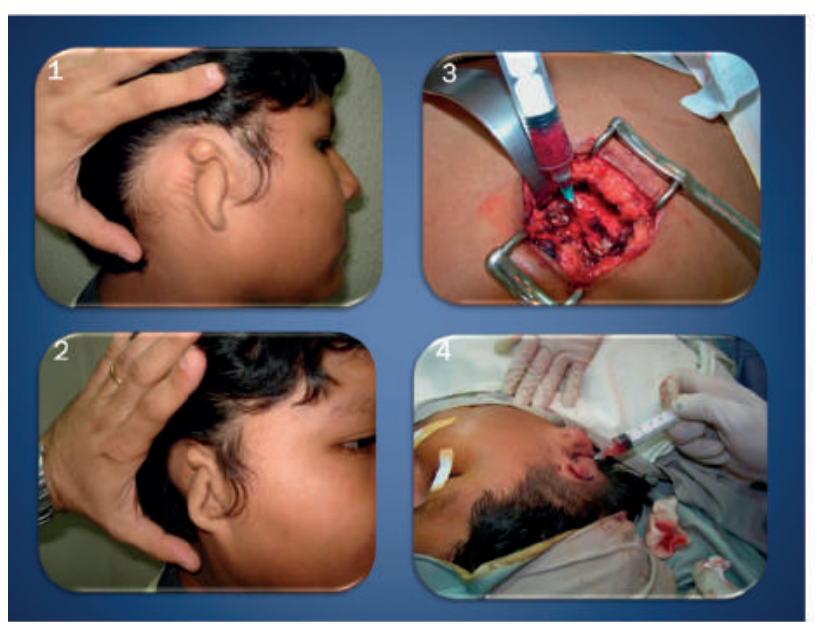

Otro caso similar de microtia severa por la clasificación de Avelar. Figura 17. Un adolescente de 13 años donde también fue sometido a reconstrucción auricular con cartílagos a utólogos, aplicamos la misma técnica inyectando en el lecho donador del cartílago la FVE de médula ósea y en el lugar de la nueva oreja, inyectamos Factores de Crecimiento Autólogos. Y tomamos una Tomografía computarizada con Reconstrucción Tridimensional (Figura 18.)a los 3 meses de post operatorio donde en el corte sagital se reporto: tejido 
de neo formación pero en menor densidad que el cartílago. Lo que podría mostrar un inicio de la regeneración tecidual local similar al del caso anterior mostrado tal vez inducido por la aplicación de la FVE de médula ósea en aquél lugar.

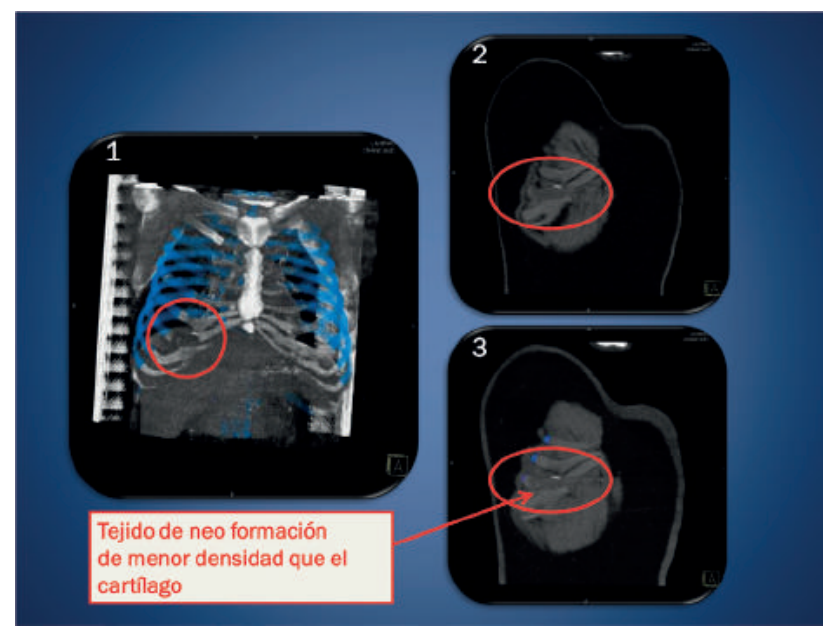

\section{Discusión}

Que es lo causaría entonces estos cambios objetivos y tan interesantes en los tejidos?

Es una renovación celular inducida únicamente por las Células Tronco del estroma? $\mathrm{O}$ son las Citocinas presentes en las células del estroma de la Medula Ósea lo que causaría este cambio en los tejidos?

O son los Factores de Crecimiento, obtenidos del plasma autólogo plaquetario, los cuales son citocinas al fin y al cabo, los únicos responsables de todos estos cambios o sino el efecto combinado y potencializado de las citocinas de la Fracción Vascular Estromal de la médula ósea.

0 es el efecto multiplicador de las citocinas del plasma plaquetario, mas las citocinas de la FVE, mas las células tronco del estroma de la FVE.

\section{Conclusiones}

Cuantificamos el número de plaquetas en todos los pacientes en los cuales aplicamos únicamente los FC y encontramos valores máximos de 427.000 por mm3. El valor mínimo fue $279.000 \mathrm{~mm} 3.0 b t e n i e n d o$ un valor promedio de $150.000 \mathrm{~mm} 3$.

A través de estos resultados creemos que valores por encima o por debajo del límite normal de la concentración sanguínea de plaquetas, no recomendamos la aplicación de los factores de crecimiento por que existen sistemas intrínsecos que bloquean la activación de los mismos.

Percibimos cambios reparativos y regenerativos en los tejidos donde asociamos la FVE y los FC, logrando una granulación y cicatrización acelerada en el caso de los pacientes quemados con una óptima integración del injerto.

Observamos una menor absorción del tejido graso injertado cuando asociamos a esta terapia regenerativa, esto tal vez por la revascularización de los tejidos alcanzada, debido al VEGFy a las células endoteliales del estroma.

Notamos cambios en la textura, elasticidad, tersura, hidratación y plasticidad de la piel en los pacientes de cirugías estéticas como en el lifting facial, por ejemplo.

Sentimos la necesidad de aclarar que todos estos cambios clínicos mencionados en todos nuestros casos estudiados y presentados se basan en la evolución clínica de cada uno, es decir en la sistematización de evaluar lo que se llama Medicina basada en evidencia, esto frente a la carencia y limitaciones de nuestro medio de no contar con otros métodos diagnósticos tal vez mas fidedignos.

La FVE libera sustancias que favorecen a la regeneración celular e interactúan con los FC, potencializando su efecto.

La FVE de la Medula Ósea tiene receptores específicos para las citocinas y son muy responsivas a esta proteína, sin embargo como no realizamos una selección especifica del tipo o clase celular durante el procesamiento de la FVE, es decir, no separamos las células tronco Hematopoyéticas de las células tronco Mesenquimales y como la FVE es altamente responsiva a esta proteína, creemos entonces que el efecto en los tejidos sea inducido en primer grado por la Citocinas y en segundo grado por las Células Tronco Mesenquimales. 0 tal vez este efecto sea producido únicamente por las citocinas. Nosotros no podemos afirmarlo.

Al tratarse de la utilización y del aprovechamiento de células autólogas no presentamos reacciones alérgicas o de rechazo en ninguno de los pacientes sometidos a esta terapia celular.

Y para finalizar, nosotros técnicamente o laboratorialmente hablando, no podemos afirmar que todos estos efectos en los tejidos sean inducidos o producidos únicamente por las células tronco de la FVE o por las citocinas únicamente.

Sabemos que las células tronco están allí aunque en menor proporción que en el tejido graso es cierto, pero como no contamos con los recursos tecnológicos necesarios para afirmar esto, pues en Bolivia no existe un Laboratorio clase 7 estándar, para que se realicen expansiones celulares, cultivos de células tronco, tipificación celular antigénica especifica o marcadores para cada una de las células, como tampoco nanotecnología o cualquier otro método moderno o avanzado. Por lo tanto nos abocamos a decir que nuestras evidencias científicas están basadas en la evolución clínica de cada uno de nuestros pacientes. De igual manera y al no tener un grupo control, algunas definiciones aparentan ser 
múltiples, inexactas e imprecisas lo que genera al mi persona como autor de este trabajo una sensación de que aún nos falta mucho por afirmar, concluir o sistematizar para poder formular un protocolo terapéutico basado únicamente en esta terapia regenerativa pero al tratarse de la utilización de sustancias autólogas con un gran potencial de regeneración y al no producir alergia ni rechazo en los tejidos, la aplicación no repercute negativamente en los pacientes siempre y cuando se emplee esta terapia.

\section{Agradecimiento}

No puedo dejar pasar esta maravillosa oportunidad para agradecer a los lectores por el tiempo depositado en la lectura de este artículo. Lealtad y gratitud constante a mi compañera de vida y co-autora del presente trabajo, la Dra. MD, Jessika Schaymann. Agradecer de corazón y humildemente al Prof. Dr. Ithamar Stocchero Nogueira, de Sao Paulo, Brasil, por el aporte importante y su contribución desinteresada para el engrandecimiento de mis conocimientos y mi ciencia que también es la ciencia y arte que Dios iluminó al profesor Ithamar.

Dirección del autor. Dr. Darío Lautaro Suárez Oyhamburú. Calle Manuel Ignacio Salvatierra, 466.entre Potosí y Tarija. Bloque B, depto. 2. Planta baja. Santa Cruz de la Sierra, Bolivia. Email: dariocirujano@yahoo.com.ar

Dirección de la Co autora. Dra. Jessika Verónica Schaymann Lora.

Calle René Moreno, 667. Clínica Medica Sirani.

Santa Cruz de la Sierra, Bolivia. Email: jvschaymannlor@hotmail.com

\section{Bibliografía}

1. Eppley BL, Pietrzak WS, Blanton M.: " Platelet -rich plasma: a review of biology and applications in plastic surgery". Plast Reconstructive Surg. 2006, 118(6): 147.

2. Eppley BL, Woodell JE, Higgins J.: "Platelet quantification and growth factor analysis from platelet-rich plasma: im- plications for wound healing" . plast reconstructive Surg. 2004, 114(6): 1502.

3. Powell, D. M., Chang, E., and Farrior, E.H.: “ Recovery from deep-plane rhytidectomy following unilateral wound treatment with autologous platelet gel". Arch. Facial Plast. Surgery. 2001. 3: 245.

4. Serra-Renom, J.M., Muñoz del Olmo, J.L. And Gonzalo Caballero, C.: Uso de los factores de crecimiento plaquetar unidos a injerto de grasa para lipofiling facial en ritidectomías". Cir. Plást.lberolatinoam. 2006, 32(3): 191.

5. Hom DB, Linzie BM, Huang TC.: "The healing effect of autologous platelet gel on acute human skin wounds". Arch Facial Plastic Surgery. 2007,9 (3): 174.

6. Monton Echeverría, J. Perez Redondo, S. Gomez Bajo, G.J."Experiencia Clínica en el empleo de factores de crecimiento autólogos obtenidos de plasma rico en plaquetas". Cir.Plast. iberolatinoam.2007, 33(3): 155-162.

7. Serra-Renom, J.M., “Aplicaciones de la inyección en Cirugia Plástica Reparadora y Estética. Nuestra evolución y estado actual”. Cir. Plást. Iberolatinoam. 2013(39): S3-S7.

8. Chajchir, A. Chajchir,G. "Injerto graso con factores de crecimiento y células madre". Cir. Plást.lberolatinoam. 2013. 39: S8-S10.

9. Almeida,KA. Campa, A. Alonso-Vale. MIC. Lima, FB. Daub, ED. Stocchero, IN. : Fraccion Vascular Estromal: Como obtener Células Madre y su Rendimiento de acuerdo a la topografía de las áreas donantes.: Estudio Preliminar, Cir.Plást. Iberolatinoam. 2008,34(1): 71- 77 .

10. Stocchero, I.N." Nociones sobre células tronco, que podemos esperar de ellas?". Cir.Plást.Iberolatinoam. 2013. 39(1): S $19-\mathrm{S} 25$.

11. Ana M. Arcuri. “Plasma Rico en plaquetas” recuperación de tejidos con factores estimulantes de crecimiento autologos'.2013.

12. German Rosani A. Medicina Regenerativa en Clínicas Estéticas y Cirugía Plástica.2014. 